\title{
Papillon - Lefevre Syndrome - A Brief Review of Diagnosis \& Management
}

\author{
Dr T.Dinesh Kumar ${ }^{1}$, Dr Ajay Kumar Pillai ${ }^{2}$, Dr Parimala Kulkarni ${ }^{3}$, \\ Dr Swapnil Moghe ${ }^{4}$, Dr Vineesh Vishnu ${ }^{5}$, Dr Saurabh Dhanraj Yadav ${ }^{6}$ \\ ${ }^{I}$ Reader, Dept. of Maxillofacial Pathology, R.V.S Dental College \& Hospital. Coimbatore.India \\ ${ }^{2,4}$ Reader, Dept. of Maxillofacial surgery. Peoples Dental Academy, Peoples University, Bhopal. India. \\ ${ }^{3}$ H.O.D. Dept of Peadodontics \& Preventive Dentistry. Peoples Dental Academy, Peoples University, Bhopal. \\ India. \\ ${ }^{5}$ Post graduate student, Dept. of Public health Dentistry, Peoples Dental Academy, Peoples University, Bhopal. \\ India. \\ ${ }^{6}$ Post graduate student, Dept. of Peadodontics \& Preventive Dentistry, Peoples Dental Academy, Peoples \\ University, Bhopal. India.
}

\section{Introduction:}

Papillon lefevre syndrome is a rare autosomal recessive disorder with a characteristic clinical features of palmoplantar hyperkeratosis with severe early onset periodontal destruction followed by the premature shedding of both the deciduous and permanent teeth ${ }^{18}$. It was first described by two French physicians papillon MM and Lefevre in 1924.

\section{Etiology}

The cause of Papillon lefevre syndrome is not well understood ${ }^{10,15}$. Recent studies indicate a cathepsin $\mathrm{C}$ gene mutation localized to chromosome 11q 14-21 is responsible for Papillon lefevre syndrome ${ }^{13,23}$. The cathepsin c-gene encodes a cysteine lysosomal protease also known as dipepitdyl amino peptidase I or cathepsin C. Cathepsin $\mathrm{C}$ is capable of removing dipeptides from the terminus of protein substrates but at higher $\mathrm{pH}$ it also exhibits dipeptidyl transferase activity. The cathepsin $\mathrm{C}$ gene is expressed in epithelial regions commonly affected by Papillon lefevre syndrome such as palms, soles, knees and keratinized oral gingiva ${ }^{16,21}$. The pathological clinical findings associated with Papillon lefevre syndrome suggest that cathepsin $\mathrm{C}$ is functionally important in structural growth and development of skin in susceptibility to periodontal disease ${ }^{19}$. It is unknown if the profound periodontal disease susceptibility is a consequence of altered integrity of junctional epithelium is eliminated, the severe gingival inflammation resolve ${ }^{\text {s10 }}$.

A variety of immunological findings have been reported in Papillon lefevre syndrome patients, including decreased monocyte chemotaxis, decreased neutrophil chemotaxis, impaired neutrophil phagocytosis, altered superoxide production and decreased response, but it has been difficult to extrapolate results of these studies $^{12}$.

\section{Clinical manifestations:}

The Papillon lefevre syndrome has a reported incidence of 1-4 cases per million person and both the sexes are equally affected and there is no racial predominance ${ }^{7}$. The age of onset is generally between 1-4 years $4,6,21$

The cardinal signs of Papillon lefevre syndrome are, palmar plantar hyperkeratosis and early onset periodontitis. In affected subjects, the development and eruption of the primary teeth proceed normally, but the eruption of these into the oral cavity is associated with gingival inflammation and subsequent rapid destruction of the periodontium. After exfoliation, the inflammation subsides and the gingiva resumes a healthy appearance, however, with the eruption of the permanent dentition the process is usually repeated, resulting in the premature exfoliation of the permanent dentition, although the third molars are sometimes spares ${ }^{9,10}$.

It can be associated with hyperhidrosis of palms and soles, resulting in a foul smelling odour, psoriasis form, scaly plaques on the elbows and knees, ectopic calcifications in choroid plexus and tentorium, follicular hyperkeratosis, hearing loss, recurrent infections, mental retardation and retinitis pigmentosa ${ }^{\mathbf{4 , 5}, \mathbf{9 , 1 4 , 2 1} \text {. }}$

We report a case of 15 year old male patient presented with the chief complaint of multiple loss of teeth. Clinical history revealed that he had normal emergence of deciduous teeth at 8-9 months of age, which started loosening at three years and were all eventually lost by four to five years of age. Patient or his guardians were not sure about the time of eruption of permanent teeth, but described gingival bleeding during brushing and eating, after the eruption of permanent teeth. There was loosening of permanent teeth from 12 years of age and eventually two permanent teeth were lost by 15 years of age. Bleeding was also associated at the time of tooth 
loss. With the complain of bleeding patient visited a local dentist who performed oral prophylaxis. Patient was normal for a couple of months but again noticed bleeding gums and then visited to our department.

The patient was moderately built with a steady gait. His physical and mental development was also normal. Medical history was noncontributory. Parents were not of consanguineous marriage. In pregnancy history of mother, she had full term uneventful pregnancy. Dermatological examination revealed dry skin with normal development of hair and nails. There were symmetric, well-demarcated, brownish, keratotic, plaques affecting the skin of his palms on the dorsal surface and soles on the ventral surface as seen in (Figure 1). Nail changes such as transverse grooving and fissuring are apparent in advanced cases

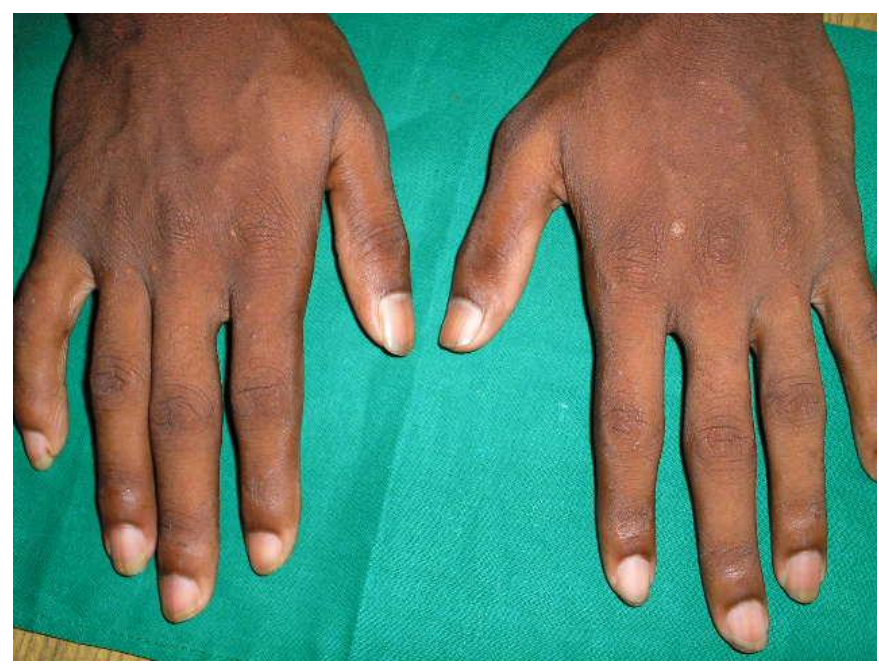

Figure 1: Keratotic Plaque on the dorsal surface of both the hand.

Intra Oral examination shows premature exfoliation of permanent maxillary and mandibular teeth. Generalized periodontitis was noticed. Prompt bleeding on probing was also noticed.

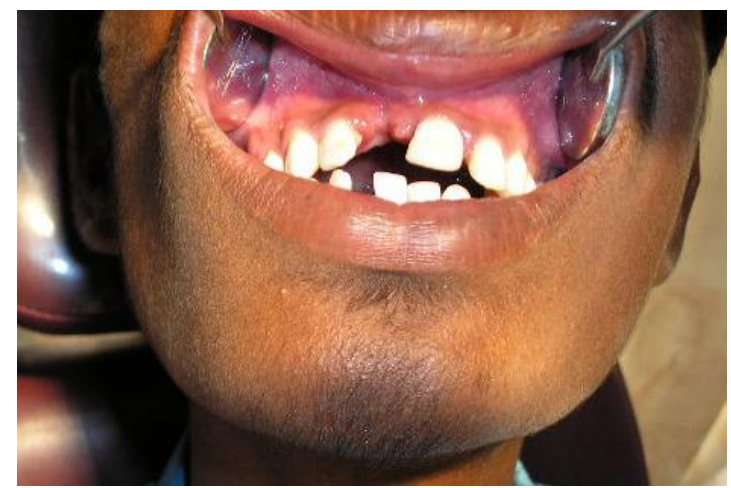

Figure 2: Intra Oral examination shows premature exfoliation of permanent maxillary teeth.

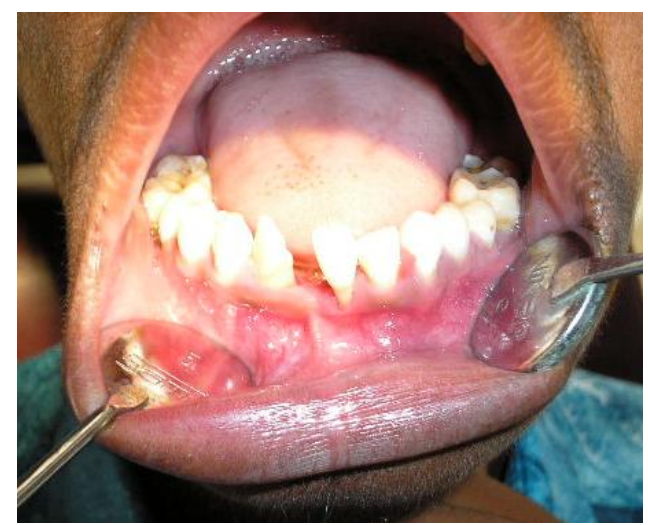

Figure 2: Intra Oral examination shows premature exfoliation of mandibular teeth. 
Panoramic view showed generalized loss of alveolar bone, complete loss of bone support around all the present teeth.

\section{Investigation and diagnosis:}

- Radiological feature is severe destruction of alveolar bone which gives the teeth a "floating in air" appearance and could be associated with intra-cranial calcifications ${ }^{24}$.

- Histopathological findings have consisted of hyperkeratosis, occasional patches of parakerotosis, acanthosis and a slight perivascular inflammatory infiltrate ${ }^{20,21}$.

- Differential diagnosis includes Hiam - munk syndrome. Both Papillon lefevre syndrome and Hiam munk syndrome are allelic variants of cathepsin c gene mutation. Both are classified as type IV palmo plantar - ectodermal keratodermos ${ }^{\mathbf{6 , 1 0 , 1 2}}$. The clinical distinction of Hiam - munk syndrome from Papillon lefevre syndrome being atropic changes of nails and arachnodactyly ${ }^{\mathbf{6 , 8 , 1 0}}$. Some suggests, Hiam-munk syndrome is a clinical variant of Papillon lefevre syndrome ${ }^{6,11}$. some times cutaneous lesions of Papillon lefevre syndrome, may be mistaken for psoriasis unless they are correlated with oral dental findings ${ }^{24}$.

\section{Treatment:}

A multidisciplinary approach is important for the case of patients with Papillon lefevre syndrome. It is usually not necessary to treat cutaneous lesions unless they interfere with patient activities ${ }^{24}$. The skin manifestations are usually treated with emollients salicylic acid and urea may be added to enhance either effects $^{\mathbf{2 1 , 2 2}}$. Periodontal treatment may consist of frequent scaling and oral hygiene instructions ${ }^{24}$. Oral retinoids including acitretin, etertinate and isotretinion are the main stay to the treatment of both the keratoderma and periodontitis associated with Papillon lefevre syndrome. Treatment may be more beneficial if it is started during the eruption and maintained during the development of the permanent teeth ${ }^{\mathbf{1 , 3 2}}$. Antibiotic therapy when incorporated delays the shedding of the teeth. Early extraction of teeth too has been advocated to prevent bony loss. Moreover this allows solid base for subsequent use of artificial dentures.

A course of antibiotics should be tried to control the active periodontitis in an effort to preserve the teeth and to prevent bacteremia and subsequent pyogenic liver abscess. The risk of pyogenic liver abscess should be kept in mind in evaluating these patients when they present with fever of unknown origin ${ }^{2,21}$.

\section{Summary:}

Papillon lefevre syndrome is a rare, autosomal recessive disorder occurring between the first and fifth years of life, which is characterized by the palmo-plantar keratoderma with periodontitis followed by the premature shedding of both deciduous and permanent teeth. The cause is not well understood but recent studies have reported that loss of function mutations affecting both the alleles of the cathepsin $\mathrm{C}$ gene. Further research at molecular level carries significant implications for understanding the susceptibility of the disease.

\section{Take Home Messege}

1. History of normal eruption of the primary and permanent Teeth.

2. Inflammed and swollen gingivae.

3. Bleeding on probing on slight provocation .

4. Mobility of teeth, with deep infra bony pockets.

5. Severe alveolar bone loss.

6. H/O of early loss of multiple teeth in case.

7. Lesions subside with exfoliation of teeth.

8. Hyperkeratotis papules present on the hands and soles.

\section{References}

[1]. AlKhenizan. S. Papillon lefevre syndrome, the response to acitretin. Int. J. Dermatol 2002 Dec, 41 (12): $938-41$.

[2]. Almuneef M, Al Khenaizam \& et al., Pyogenic liver absess and Papillon Lefevre syndrome: not a rare association. Pediatrics, 2003 Jan; 111 (1): e85-88.

[3]. Blanchet Badon C, Nazzaro V et al., Acitretin in the treatment of severe disorders of Keratinizaiton. Results of an open study. J. Am. Acad Dermatol 1991 Jun; 24 (6 Pt-1) 982-6.

[4]. Cury, VF, Costa JE et al., A Novel mutation of cathep C gene in papilon lefevre syndrome. J. periodontal. 2002 March; 73 (3): $307-$ 12.

[5]. Gorlin RJ, Pindborg JJ, Cohen M.M. Jr. et al., syndromes of the head and neck, $2^{\text {nd }}$ ed, New York ; Mc Graw Hill, $1976 ; 373-376$.

[6]. Gorlin RJ, Sedano. H, Anderson VE, et al., The Syndrome of Palmar Plantar hyperkeratosis and premature periodontal destruction of the teeth. J. Pediatr. 1964, 65: 895-908.

[7]. Griffiths WAD, Judge MR et al., Disorders of Keratinization, In: Champion RH, Burton JL, Burns DA, Breathnach SM Editors. Text book of dermatology, $6^{\text {th }}$ edition, Oxford Black well scientific Publications, 1988; pp : 1569-1571 
[8]. Haim S, Munk J. et al., Keratosis palmo plantaris congenita, with periodontosis, arachnodactyly and peculiar deformity of the terminal phalanges, Br. J. Dermatol. 1965, 77: 42-45

[9]. Haneke E. The Papillon Lefevre syndrome: Keratosis palmoplantaris with periodontopathy. A report of a case and review of the cases in the literature. Hum genet, 1979, 51: 1-35.

[10]. Hart T.C. et al., Mutations of the cathepsin C gene responsible for papillon lefevre syndrome. J. Med Genet. 1999; 36: 881-887.

[11]. Hart Tc, Hart Ps, Firatli E, Haim Munk Syndrome and Papillon Levre syndrome are allelic mutations in cathepsin C. J. Med Genetics, 2000 Feb; 37 (2): 88-94.

[12]. Hart, TC, Shapira, Papillon lefevre syndrome, periodontal, 2000, 1994, 6: 88-100.

[13]. Hart. TC, Bowden DW, Ghaffar KA, et al., Sublocalization of the Papillon - Lefevre syndrome locus on 11q, 14-q21. Am. J. Med Genet. 1998, 79: 134-139.

[14]. Identification of cathapsin c Mutations in ethnically diverse papillon - lefevre syndrome patients. 2000, 37: 927-932 (December).

[15]. Itin PH; classification of autosomal Palmoplantar Keratodema; past present, future, dermatology 1992; 185: 163-165.

[16]. Kirschke H, Barett AJ, Rawlings ND. Proteinases : Lysosomal cystein proteinases In: Sheterline p, ed. Protein Profile. Vol 2, London, Academic Press, 1995: 1587-643.

[17]. On line mendelian inheritance in man, OMIM (TM). John Hopkins University, Baltimore, MD. MIM Number: (MIM 245000): (7/27/00): World Wide WRB VRL: http://www.ncbi.nlm.nih.gov/omim.

[18]. Papillon MM, Leferve, P. Deux cas de keratodermie palmaire et plantaire symetrique familiale (maladie de meleda) chez le frere et la soeur. Coexistence dans les deux deux cas d'alterations dentaires grabes. Bill soc dermatol syphilis 1924; 31: 82-87.

[19]. Rao NV, Rao GV, Hodial JR et al., Human di peptidyl Peptidase, 1, J. Biol, Chem 1997; 272: 10260-5.

[20]. Reyes Vo, King - Ismael D, et al., Papillon lefevre syndrome. Int. J. Dermatol, 198, Afr, 37 (4): 268-70.

[21]. Shahbaz A Janjva MD, Khachemoune, MD et al., Dermatology online journal 10(1): 13: 1-7.

[22]. Siragusa M, Ramanoc et al, A new family with Papillon lefevre syndrome: effectiveness of etretinate treatment. Cutis 2000 Mar, 65 (3): $151-5$.

[23]. Toomes C, James J, Wood AJ, WU CL, Mc Cormick. D, Lench N, Hewittc, Moynihan. L. et. al. Loss of function mutations in cathepsin-C gene result in periodontal disease and palmoplantar keratosis Nat. Genet. 1999. Dec; 23 (4): 421-4.

[24]. Vikram K. Mahajan, Narbir. S. Thakur et al., PLS Indian Pediatrics, 2003, vol. 40 (Dec 17): 1197-1200. 